\title{
Programmable Logic Controller (PLC) in Automation
}

\author{
Mallikarjun G. Hudedmani*, Umayal R M, Shiva Kumar Kabberalli, Raghavendra Hittalamani \\ Department of Electrical and Electronics Engineering, KLE Institute of Technology, \\ Opposite to Airport, Gokul, Hubballi, Karnataka, India
}

dai: https://doi.org/10.21467/ajgr.2.1.37-45
${ }^{*}$ Corresponding Author email:
mallikarjunh@yahoo.com
Article Histary
Received: 20 March 2017
Revised: 21 May 2017
Accepted: 23 May 2017
Published: 24 May 2017
Student(s)
- Umayal R M
- Shivakumar Kabberalli
- Raghavendra Hittalamani
Academic Year: 2016-17, Even Semester
Course Level: Bachelor Degree
Course Name: BE (Electrical \& Electronics
$\quad$ Engineering)
Course year: $4^{\text {th }}$ year / VIII ${ }^{\text {th }}$ Semester
Mentar(s)
Mallikarjun G. Hudedmani

dai: https://doi.org/10.21467/ajgr.2.1.37-45

* Corresponding Author email:

mallikarjunh@yahoo.com

Article Histary

Received: 20 March 2017

Revised: 21 May 2017

Accepted: 23 May 2017

Published: 24 May 2017

Mallikarjun G. Hudedmani

\begin{abstract}
The programmable Logic Controller (PLC) is the central controlling unit in the industry or a process. The effective operation of the process and safety considerations if programmed appropriately can meet the required objectives. The present technical paper briefly distinguishes the present automation systems and the past technologies to identify and explore the capabilities of PLCs for any process. The relay logic and contactor logics (RLC) were practiced in the olden days which include the human intervention and errors. The advent and application of microprocessors, microcontrollers and new specific tools such as PLCs, Supervisory control and data acquisition (SCADA) and Distributed control systems (DCS) have increased productivity, accuracy, precision and efficiency. These systems reduced human intervention and increased the flexibility in the process control. The keyword automation clearly states that the working of a process or repetition in an efficient manner by incorporating mechanisms and control sequences in the proper order several times with acceptable deviations in the output of the process.
\end{abstract}

Keywords: Automation, PLC, Logic control, SCADA and DCS

\section{Introduction}

The meaning of the word Automation is self-dedicated derived from Greek literature. Automation helps to improve productivity by modernizing and increasing the work efficiency. It is the process of having machines follows a predetermined sequence of operation with or without human intervention in a manufacturing process [1]. The main objectives of automation are integration of manufacturing processes, increased safety level of operator as well as work piece to increase productivity, improve quality, efficiency and reduce labor cost as well as the human errors. For the automation of a process the basic requirements are namely, power source, suitable input and out puts, proper feedback and commands [2-3]. The present automation has taken series of transformation from Relay and contactor logic, Programmable logic controller (PLC), Supervisory control and data acquisition (SCADA) and Distributed control system (DCS) in steps [4-6]. The choice of specific method goes with the problem and area of application. The gain and 
Hudedmani et al., Adv. J. Grad. Res.; Vol. 2 Issue 1, pp: 37-45, July 2017

increased output is highly noticed after the installation of automatic controls incorporating suitable techniques. Currently the automation using PLCs is increasing rapidly in all the sectors to evidence efficiency and profit [7]. The MODICON 084 was the world's first PLC commercially produced by Bedford associates [8].

\section{Comparative Study of Different Techniques in Automation}

From the literature, it is very clear that every process for its effective operation need specific set of instructions and necessary infrastructure. The processes operated by human or non-automated yield lesser productivity and may not be energy efficient but such practices were inevitable till the advent of the concept automation. The Automation brought the revolution in every field of application to a greater extent incorporating technologies and machines to do activities in efficient manner by reducing human intervention. In the following paragraph comparative study of such methods is done.

\subsection{Relay and Contactor Logic}

Relay and contactor logic use relay which is an electromagnetic switch which opens and closes the contacts to control electrical circuit like as shown in Figure 1. The energized coil with a suitable supply controls the circuit. A simple RC circuit is usually installed across the coil to dissipate and absorb the spikes of voltages which may damage the coil winding. Similar to this a contactor is an electrically controlled switch used for switching a power circuit activated by a control input. Contactors unlike a circuit breaker are not intended to interrupt a short circuit current. A contactor generally consists of Power Contacts, Auxiliary Contacts and Contact Springs etc.

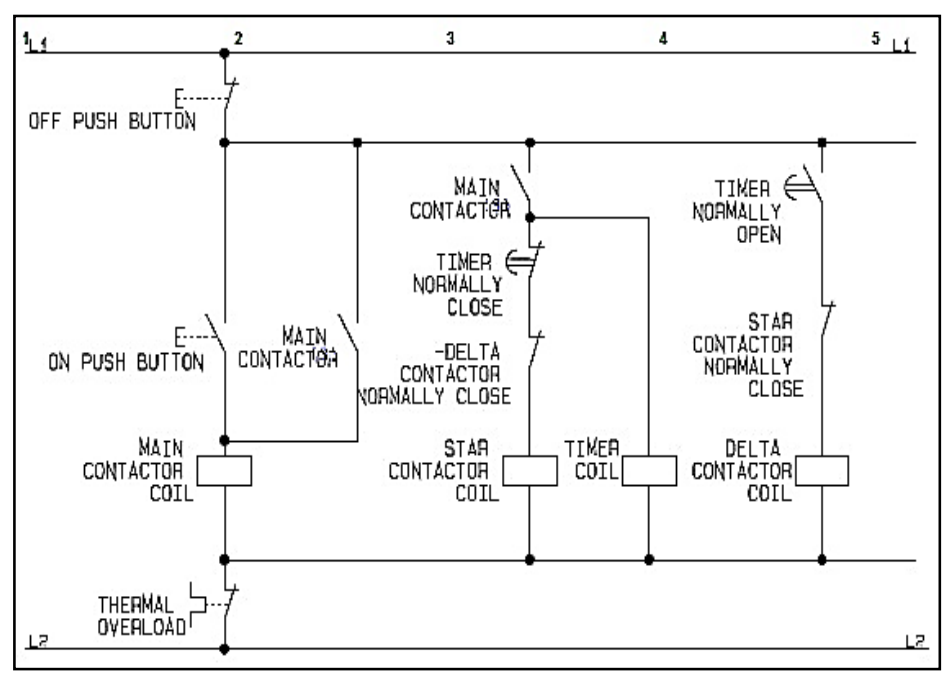

Figure 1: Sample Star Delta starter circuit

The electromagnet is the main driving element which closes the contacts. Generally, it is enclosed in a housing made up of insulating materials. The major drawback of relay and contactor logic is it needs immediate rectification on failure and it does not possess any redundant system.

\subsection{Supervisory Control and Data Acquisition (SCADA)}

SCADA is an acronym for Supervisory Control and Data Acquisition system. It is software with necessary hardware to accomplish the task assigned. SCADA is a computer system gathers and analyzes the data on real time. SCADA is used to monitor and control a plant or equipment in industries such as energy system, sugar, ceramic, cement, power, telecommunications, water and waste control, oil and gas refining and transportation etc. SCADA intern need PLC, necessary control mechanism, communication systems to fetch the data or information from the field and control effectively. The role of operator in SCADA system is very important and crucial. A well-organized SCADA maximizes the system benefits. The present generation SCADA systems are very highly motivated by the strategic skills and control sets to optimize and maximize the operational benefits of its installation. The Figure 2 shows a typical SCADA with associated components for its proper functioning. The details of individual sub blocks are presented in the following paragraph.

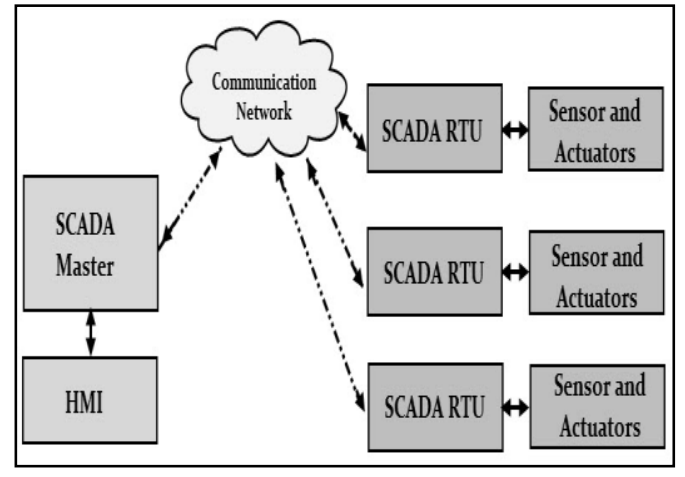

Figure 2: SCADA with Field Instrumentation 
Programmable Logic Controller (PLC) in Automation

\subsubsection{Remote Terminal Unit (RTU)}

RTU is a device installed in the field or a remote location from where it collects data, codes and transmits to the central station or master. The RTU may be a PLC gathering the required field data and status of all installed devices. The other role RTU collects information from the master device and implements and processes at the field for the requirements. The mode of communication involve wired and wireless as per the scope.

\subsubsection{Master Terminal Unit (MTU)}

MTU is the infrastructure installed at the Master Station for communicating with the RTUs and PLCs, etc, through human machine / man machine interface (HMI/MMI) with suitable software running on computer terminals in the control room. This unit preprocess the data receive and stores it into the data base. Main program written to control the entire process scans and use this data and updates it. The MTU communicate with field via RTUs.

\subsubsection{Field Instrumentation}

The SCADA needs a lot of instrumentation like, the sensors, switches, actuators, valves and other feedback devices that are connected to the equipment or machines being controlled and monitored by the SCADA system. The SCADA RTU is a PLC or small industrial computer which allows the central SCADA to communicate with the field devices.

\subsection{Distributed Control System (DCS)}

Distributed control system (DCS) is a control system in which the controller elements are not central in location but are distributed throughout the system for the ease of control and management. In this system, each component or sub system is controlled by one or more controllers. The entire system of controllers is connected by a network for communication and monitoring. General examples are like large processing units or manufacturing systems, processes or any kind of dynamic system. A typical DCS system is shown in Figure 3 and its sub components are described as below.

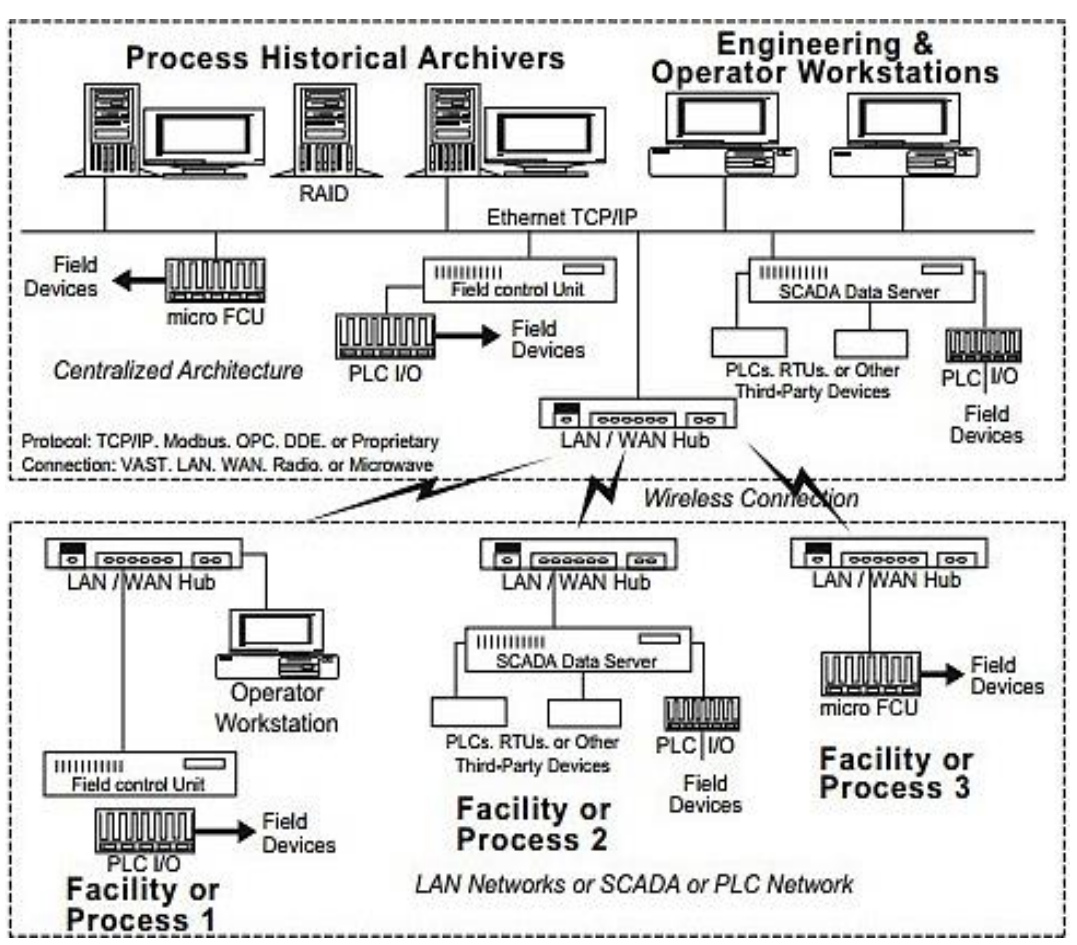

Figure 3: Architecture of Distributed Control Systems (Source: Control Systems International, Inc)

\subsubsection{Engineering Workstation}

The Engineering Workstation (EWS) is used to set up project development, configuration of graphics, logic, alarms, security etc for the system wide use and operation.

\subsubsection{Process Historical Archives}

The Process Historical Archives (PHA) stores and retrieves historical data collected by the FCU, micro FCU, or any other intelligent device in the system. 


\subsubsection{Controllers to Monitor Field Devices}

The monitoring of the field devices is very necessary on real time basis Field Control Unit (FCU) is used. It is typically a PLC/industrial computer. The FCU executes sequential and regulatory logic and directly scans I/O of the field devices depending on the FCU's configuration.

\subsubsection{Networking and Communications}

For the good control and operation, a wide spread communication networks consisting of Fiber optic and Ethernet local using the TCP/IP networking protocol with necessary firewalls need to be installed and used for the security of the data and safety of the operation.

\section{Programmable Logic Controllers (PLC)}

Programmable Logic Controller (PLC) is globally known as the 'work horse' of industrial automation. Its invention was to replace the large sequential relay circuits for machine control. PLCs were first introduced in the late 1960's. Bedford associates (Bedford, MA) proposed a Modular Digital Controller (MODICON) to a major US car manufacturer. The MODICON 084 is the world's first PLC commercial production by Bedford associates [8]. Earlier to this Sequencer state-machines were found in the mid1970's. The standardization of communications among different PLCs was initiated in 1980's and finalized in 1990. Considerations in the choice of suitable PLC with the large choice of options are now available from several original equipment manufacturers (OEM). For a specific requirement or certain function or input/output, it is possible that one system from a single manufacturer standing out as more superior or cost effective than the other. To determine the most suitable PLC to be used in the automation task need several basic considerations to be made namely, number of input/outputs, digital/analog I/O, memory capacity needed, speed and required power for the CPU and coding instructions, manufacturer's service support etc. All these parameters are interdependent and choice need to be judicial. The PLC mainly consists of a central processing unit (CPU), memory and $\mathrm{I} / \mathrm{O}$ modules to handle input/output data. PLCs have the basic structure as shown in Figure 4. PLC has four main units and discussed below.

\subsection{The Program Memory}

It is the memory space where the program instructions for the logical control sequence is stored.

\subsection{The Data Memory}

The status of inputs/outputs like, switches, interlocks, previous values of data and other working data is stored.

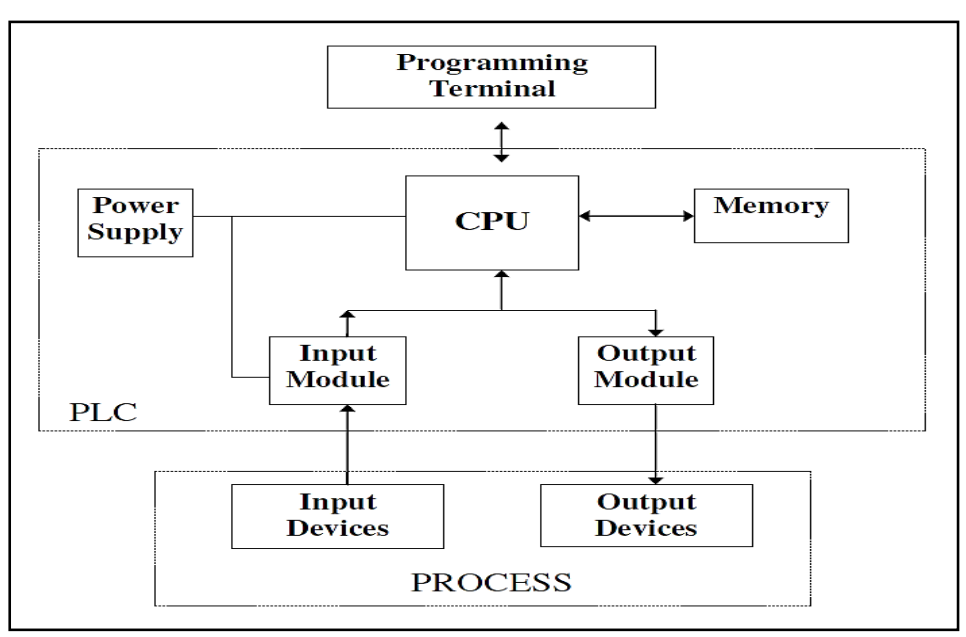

Figure 4: Block diagram of PLC with I/O

\subsection{The Input Devices}

These are the hardware/software inputs from the field from the industrial process. The signals may be from sensors, switches, proximity detectors and interlock settings etc. These inputs trigger the sequences in user program for the required output or a process. For example, Emergency stop input is always monitored by the PLC program and as when this switch is hit by incident or accident the whole PLC process is suspended to a halt situation. 


\subsection{The Output Devices}

The solenoid valves and pneumatic actuators, motors, heaters, cooling fan motors, alarm indicator and buzzers are the typical output devices. These devices drive the industrial processes. The alarm indicator output mostly with audio visual warn the operator of the process for the unexpected happening in the sequential process currently running for the proper attention. In order to program the PLC a programming unit is necessary which may be a personal computer with suitable software to interface the PLC. The programming unit helps to build, test and edit the logical sequences that the PLC will execute repeatedly in the real process. The IEC 61131-3 standard explains the different programming methods for PLCs namely, Sequential Function Chart, Function Block Diagrams and Ladder logic. Standards are needed for the exchange of information or data among the PLCs of different manufactures. PLC contains both Random access memory (RAM) and Read only memory (ROM) in varying capacities depending upon the application and design. The PLC work by scanning its inputs and depending on their state, turns ON/OFF relevant outputs. PLC continuously scans the user program which is presented in Figure 5.

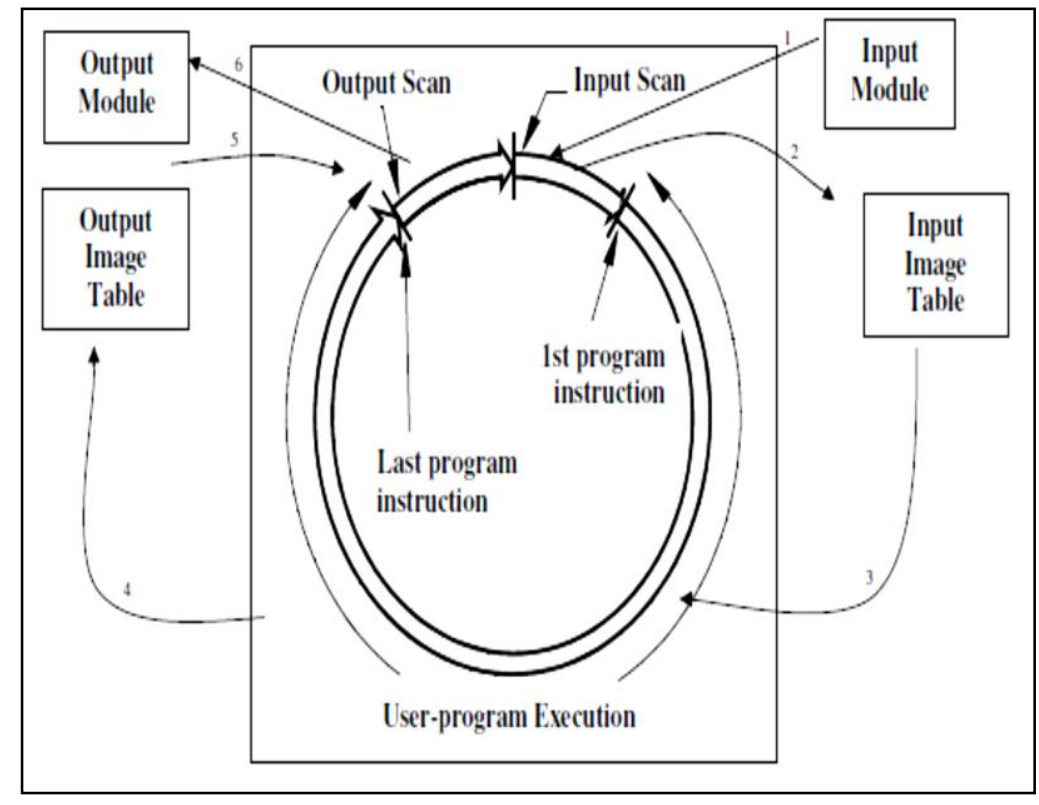

Figure 5: Scanning sequences in PLC

\subsubsection{Input Scan}

During the input scan, the current status of every input module is stored in the input image table for the proper update. This is done by monitoring every input device connected to the input modules and updating its current state into the input memory table. PLC program on its run checks the conditions of inputs and executes its controls via output. The much-updated status of the input image is very necessary for the PLC.

\subsubsection{Program Scan}

Upon the completion of input scan CPU enters into its user program execution or simply program scan. The execution involves step by step processing up of instructions starting at the program's first instruction to the last instruction. During the user-program execution the CPU continually update its output image table up-to-date so that desired activities are performed as when initiated by a suitable condition.

\subsubsection{Output Scan}

During program scan, the output modules themselves are not kept continually up to date. Instead, the entire output image table is transferred to the output modules during the output scan which comes after the program execution. Thus, the output devices are activated accordingly during the output scan. Finally, a PLC checks each of its input with intention to see which one has status on or off and the action might be activation of certain outputs. Changes are performed based on the input status that has been

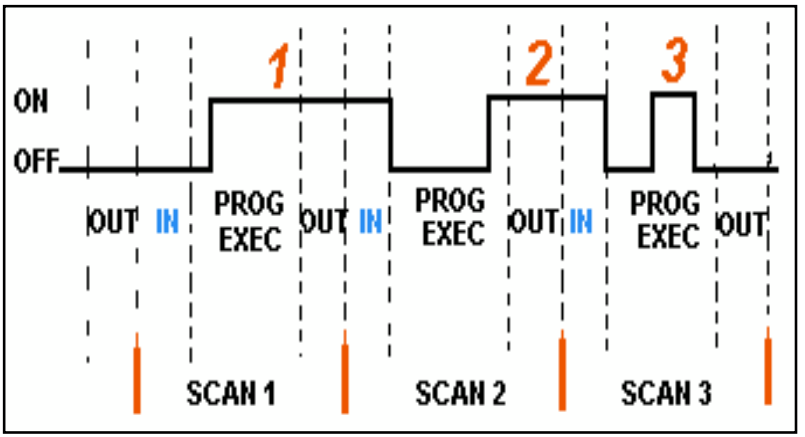

Figure 6: Scan time in PLC 
Hudedmani et al., Adv. J. Grad. Res.; Vol. 2 Issue 1, pp: 37-45, July 2017

read during the first step and based on the result of the program execution in step two following execution of step three PLC returns a beginning of the cycle and continually repeats these steps as shown in Figure 6.

$$
\begin{array}{ccc}
\text { Scanning time }=\text { Time for performing }+ \text { Time for performing }+ \text { Time for performing } \\
\text { step } 1
\end{array}
$$

Programmable Logic Control is very much useful in the production processes which undergo a fixed repetitive sequence of operations that involve logical steps and decisions. A PLC is used to control, time and regulate the sequence. Small PLCs are able to control a medium scale automatic machining station or chemical process. Large PLC systems are capable of running entire factory automation. Industrial production processes follow a fixed sequence of actions that are determined by the identified steps in the production assembly line, processing of raw materials, the formation of chemical or pharmaceutical products in a chemical process etc.

\section{Elements of Ladder Logic and a Practical Example}

The basic components in a ladder logic program are the contact and the coil. The contact is the name given to a general input device set by an external switch, an internally set logic or timer function. Coil is the name given to an output device and is used to drive relays, contactor, motors, solenoids and other process actuators.

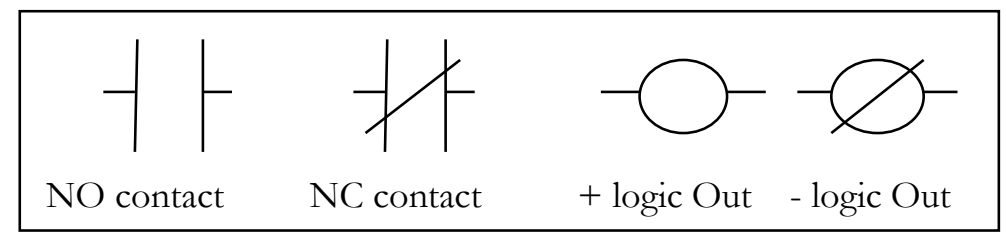

Figure 7: Basic Ladder Logic Components Figure 7 shows the few such contacts used in Ladder programming namely, normally open, normally closed, logic high out and logic low out. A typical oil tank level control mechanism as shown in Figure 8 is taken for a study example for the understanding of the working of PLC. Chosen inputs and outputs for the example are listed in Table 1. Initially the tank is empty. The status of low level and high-level probes is logic High (No Oil). Therefore, input 0000 is TRUE (Logic High) and input 0001 is also TRUE (Logic High). A sample ladder diagram is as shown below.

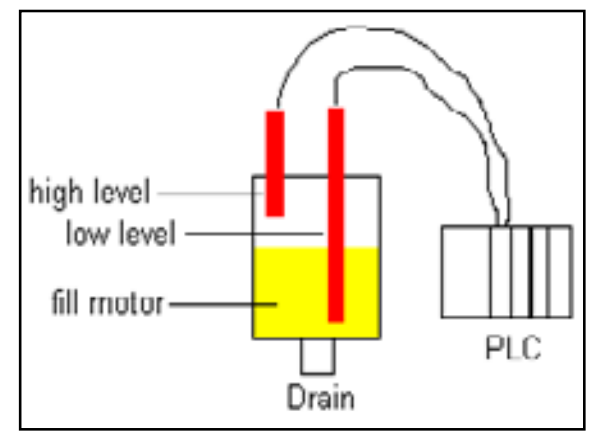

Table 1: I/O's of PLC based Oil dispenser

\begin{tabular}{|c|c||c|c||c|}
\hline Inputs & Address & Output & Address & $\begin{array}{c}\text { Internal } \\
\text { Utility } \\
\text { Relay }\end{array}$ \\
\hline Low level sense & 0000 & Motor & 0500 & 1000 \\
\hline High level sense & 0001 & & & \\
\hline
\end{tabular}

Figure 8: PLC based Oil dispenser

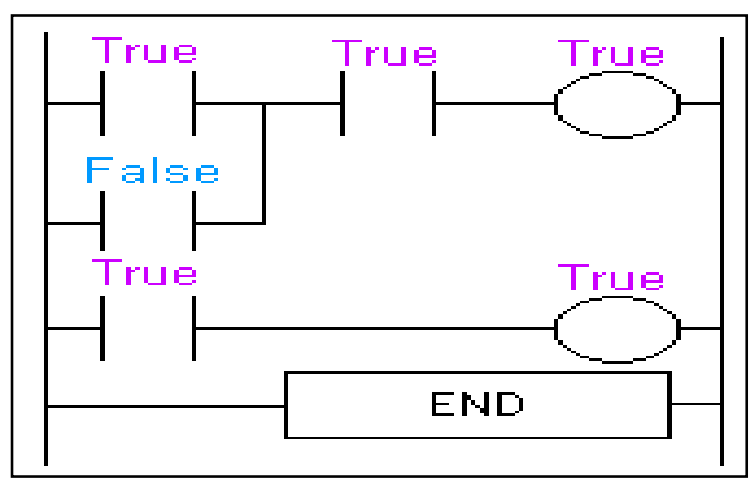

Figure 9: Ladder diagram with $1 / O$

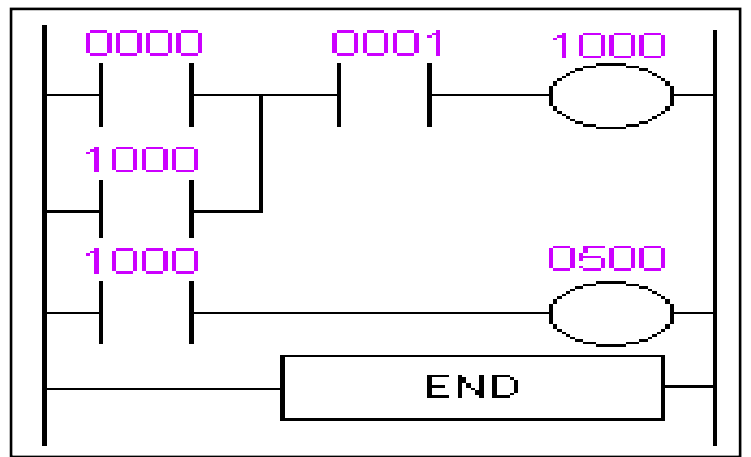

Figure 10: Sets up output 500 High 


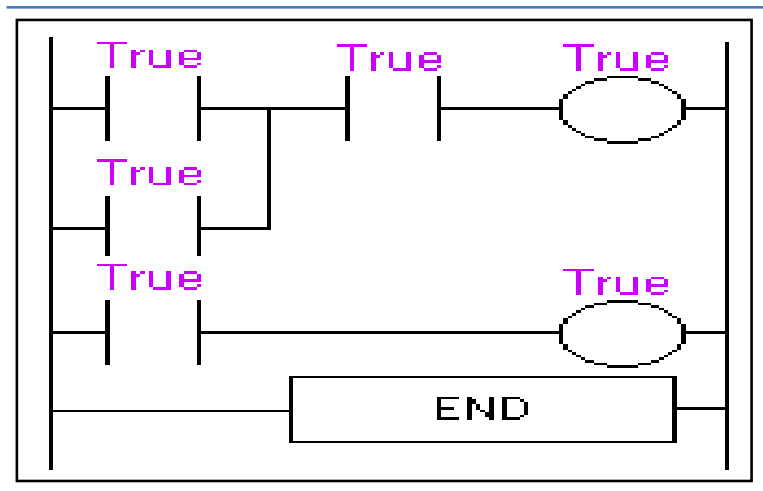

Figure 11: Output is Latched

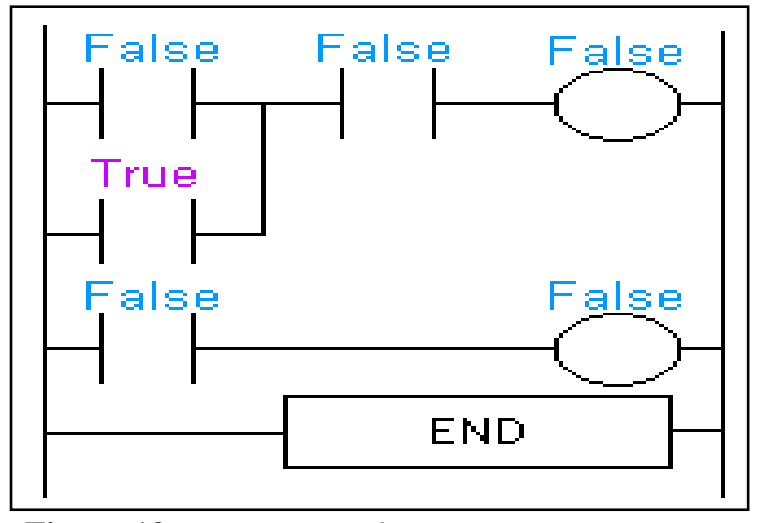

Figure 13: Output turned OFF

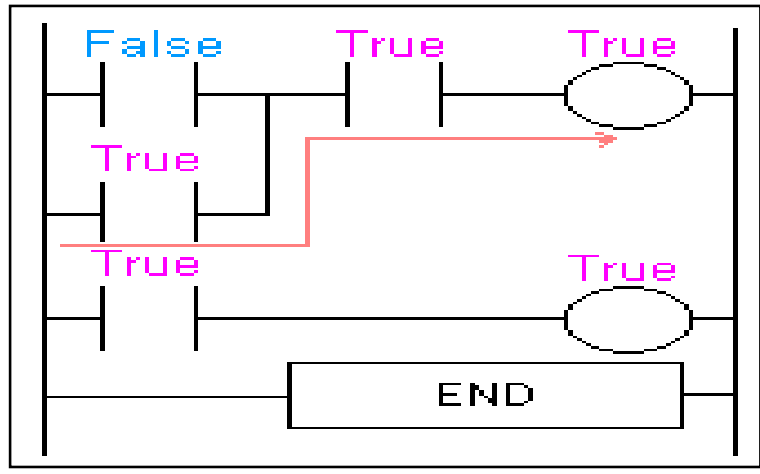

Figure 12: Output is Latched even though low level sensor is open

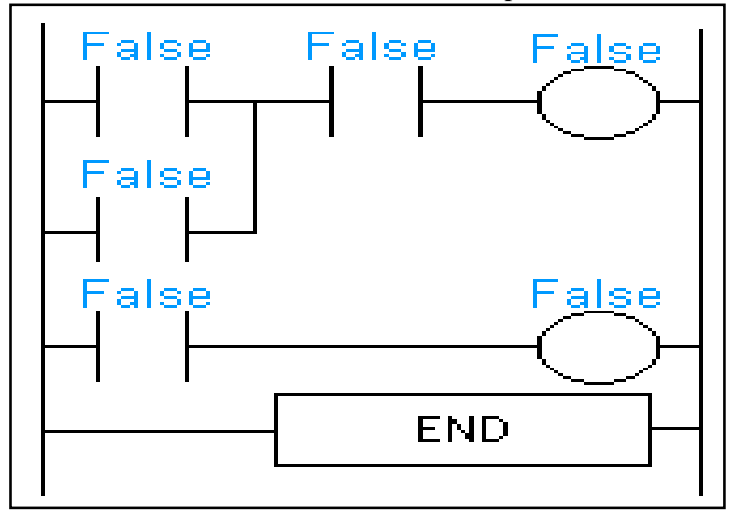

Figure 14: Complete turn OFF of the sequence

Figure 9 to Figure 14 show step wise logic conditions and execution of Ladder steps to setup output and turns OFF once the tank is full. The gradual filling up of tank takes place because of output 500 (Pump motor). After the oil level rises above the low-level sensor and it becomes open (FALSE) there is still a path of TRUE logic from left to right. This is because of internal relay. Relay 1000 is latching the output 500 "ON". It will stay ON until there is no true logic path from left to right (or when 0001 becomes false). After the oil level rises above the high-level sensor it becomes open (FALSE). Since there is no more TRUE logic path, output 500 is no longer energized (TRUE) and therefore the motor turns OFF. After the oil level falls below the high-level sensor and it will become TRUE again the entire sequence repeats again. Table 2 shows the overall comparison of different control methods for the respective choice in automation.

Table 2: Typical comparison of different control methods

\begin{tabular}{|c|c|c|c|c|}
\hline Characteristics & Relay Logic & Digital/Analog Logic & PLC systems & $\begin{array}{c}\text { SCADA/ } \\
\text { Computer }\end{array}$ \\
\hline Cost per function & Low & Low & Low & High \\
\hline Overall size & Bulky & Very compact & Very compact & Compact \\
\hline Operating speed & Slow & Very fast & Fast & Faster \\
\hline $\begin{array}{lll}\begin{array}{l}\text { Electrical noise and } \\
\text { immunity }\end{array} & & \\
\end{array}$ & Excellent & Good & Good & Good \\
\hline Installation & $\begin{array}{c}\text { Time } \\
\text { consuming }\end{array}$ & $\begin{array}{l}\text { Time consuming in } \\
\text { design and tuning }\end{array}$ & $\begin{array}{l}\text { Simple to } \\
\text { program }\end{array}$ & $\begin{array}{l}\text { Time consuming in } \\
\text { programming }\end{array}$ \\
\hline $\begin{array}{l}\text { Ability to handle } \\
\text { complex functions }\end{array}$ & No & Yes & Yes & Yes \\
\hline $\begin{array}{ll}\begin{array}{l}\text { Flexibility } \\
\text { modification }\end{array} & \text { in } \\
\end{array}$ & Very Difficult & Difficult & Very simple & Simple \\
\hline Maintenance & Very difficult & Not easy & Good & Not easy \\
\hline
\end{tabular}


Hudedmani et al., Adv. J. Grad. Res.; Vol. 2 Issue 1, pp: 37-45, July 2017

Table 3: Pros and cons associated with each control methods

\begin{tabular}{|c|rll|}
\hline Control Method & & \multicolumn{1}{c|}{ Pros and cons } \\
\hline \multirow{4}{*}{ Relay and contactor Logic } & i. & Simple design and easy to assemble \\
& ii. & Easy to understand (smaller systems), larger space occupancy and not \\
& flexible (larger systems) \\
& iv. & Costlier frequent maintenance \\
& v. & Larger relays need additional driver circuits \\
& vi. & Rigan intervention cannot be avoided adjustments and no intermediate controlling other than ON/OFF \\
vii. & Increases electrical noise and interference \\
\hline \multirow{3}{*}{ SCADA system } & i. & Monitor entire system on real time basis being Modular and Scalable \\
& ii. & Accessing specific element/ plant area and user friendly with \\
& iii. & messages/alarms \\
& iv. & pontinuous data log and updates of events for the analysis and future \\
& v. & Heavy infrastructure huge cabling and instrumentation sensors etc \\
& i. & Eage initial investments \\
\hline \multirow{5}{*}{ DCS system } & ii. & Modular and Scalable with higher Reliability \\
& iii. & Less Cabling and limited distributed intelligence \\
& iv. & Good fault tolerance \\
\hline PLC system & i. & Flexible and custom to application \\
& ii. & Process capability and reliability increases \\
& iii. & Moderate Cabling and incorporates intelligence \\
& iv. & Good fault tolerance and reparability \\
\hline
\end{tabular}

\section{Conclusions}

The good automation and process control is very necessary in the competitive world. Rapid production changes and attainment of good production with minimal waste is really challenging. The PLC based automation works will surely turn the production activities into profit. The complex operations and reduction in set up time can be greatly reduced by making use of PLC based automation. The works in ceramic, cement, chemical, a food processing, packaging industry and so on strongly requires the use of PLC systems for the great profit and performance. The comparative study of historical growth in automation evidenced the current world and its challenges with PLC. The innovative developments and opportunities to invest in such automation is the hurdle right now with the related economy. Present work explored the control schemes for industrial automation and system monitoring to improve system operation, system reliability etc. Various types of automation systems such as relays, contactor logic, PLCs, SCADA and DCS have been discussed also, Pros and cons associated with each control methods have been summarized in Table 3. The DCS, SCADA and communication systems integrate protection, control and monitoring together to maximize the benefits. Truly, automation and system monitoring are the logical choice to improve system performance and to achieve customers and shareholder's satisfactions.

\section{How to cite this article:}

Hudedmani, M., Umayal, R., Kabberalli, S., \& Hittalamani, R. (2017). Programmable Logic Controller (PLC) in Automation. Advanced Journal of Graduate Research, 2(1), 37-45. doi: https://doi.org/10.21467/ajgr.2.1.37-45

\section{References}

[1] Subhasini Dwivedi, Michael Fernandes, Rohit D'souza, “A Review on PLC based Automatic Waste Segregator” International Journal of Advanced Research in Computer Engineering \& Technology (IJARCET), Vol 5 no 2, pp 280-285, 2016.

[2] Sudeep Kelaginamane, Sridhar D. R., "PLC Based Pneumatic Punching Machine" Journal of Mechanical Engineering and Automation, 
Programmable Logic Controller (PLC) in Automation

vol 5, no (3B), pp 76-80, 2015.

[3] Helen Maria Sabu, Aravind V.B, Apurva Sullerey and Binson VA, "Online Monitoring of PLC Based Pressure Control System" International Journal of Research and Innovations in Science and Technology, Vol 2, no 2, pp 47-50, 2015.

[4] Richa Netto, Aditya Bagri, "Programmable Logic Controllers" International Journal of Computer Applications, Vol177, No.11, pp 2731, 2013.

[5] Maha M. Lashin, "Different Applications of Programmable Logic Controller (PLC)" International Journal of Computer Science, Engineering and Information Technology (IJCSEIT), Vol. 4, No. 1, pp 27-32, 2014.

[6] D. V. Pushpa Latha, K. R. Sudha, Swati Devabhaktuni, "PLC based Smart Street Lighting Control" I.J. Intelligent Systems and Applications, vol 06, no 1, pp 64-72, 2013.

[7] Burali Y. N, "PLC Based Industrial Crane Automation \& Monitoring" International Journal of Engineering and Science, Vol. 1, no 3, pp 01-04, 2012.

[8] Alison Dunn, "The father of invention: Dick Morley looks back on the 40th anniversary of the PLC" Manufacturing Automation, 2008, accessed on May 23, 2017.

\section{Publish your research article in AIJR journals-}

$\checkmark$ Online Submission and Tracking

$\checkmark$ Peer Reviewed

$\checkmark$ Rapid decision

$\checkmark$ Immediate Publication after acceptance

$\checkmark$ Open Access (Articles freely available online)

$\checkmark$ Retain full copyright of your article.

Submit your article at journals.aijr.in 